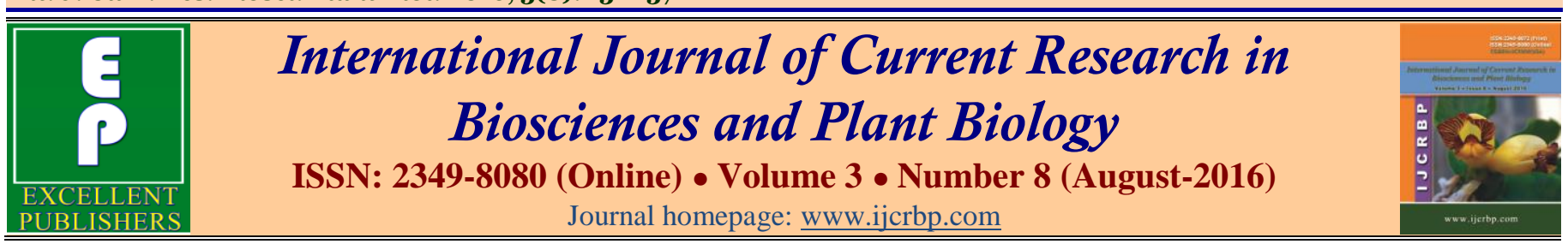

\title{
In Vitro Anti-infective and Antioxidant Activity of Plumbago zeylanica Linn.
}

\author{
John Antwi Apenteng*, Marianne Gloria Brookman-Amissah, Christina Osei-Asare, \\ Esther Eshun Oppong and Monilola Ogundeyi
}

Department of Pharmaceutical Science, Central University, Accra, Ghana

*Corresponding author.

\begin{abstract}
A bstract
Plumbago zeylanica (Plumbaginaceae) is a perennial shrub with semi woody stems and numerous branches. It is used in Africa and Asia for the treatments of common ailments such as haemorrhoids, diarrhoea, leprosy, acute inflammation and cuts. This study aims at evaluating the antimicrobial, anthelmintic and antioxidant activities of $P$. zeylanica methanol and ethyl acetate leaf extracts. The antimicrobial activity was evaluated by determination of the minimum inhibitory concentration using the micro-broth dilution method against selected microorganisms. Anthelminthic activity was evaluated by determining the in vitro paralysis and death times of the extracts on Pheretima posthuma at concentrations of 300,100 and $30 \mathrm{mg} / \mathrm{mL}$. Antioxidant activity was conducted by 2, 2- diphenyl-1-picrylhydrazyl (DPPH) free radical scavenging method. Results revealed that both extracts had antimicrobial activity. Significant anthelminthic activity was observed at $30,100(p<0.001)$ and $300 \mathrm{mg} / \mathrm{mL}(p<0.05)$ with ethyl acetate extract being a more potent anthelminthic agent. The ethyl acetate extract showed better antioxidant activity with inhibitory concentration $\left(\mathrm{IC}_{50}\right)$ of $0.29 \mu \mathrm{g} / \mathrm{mL}$ as compared to that of the methanol extract $(2.33 \mu \mathrm{g} / \mathrm{mL})$. The ethyl acetate extract showed better antiinfective and antioxidant activity than that of methanol. Phytochemical screening of the plant revealed the presence of alkaloids, glycosides (saponins, anthraquinones), tannins and flavonoids.
\end{abstract}

\section{Article Info}

Accepted: 28 July 2016

Available Online: 06 August 2016

Keywords

Antimicrobial

Antioxidant activity

Pheretima posthuma

Phytochemicals

Plumbago zeylanica

\section{Introduction}

Over the past few decades there has been an increased interest in natural materials as sources of drug. Natural products from plant, animal or other living matter have contributed greatly to the future of medicine. However, plant products have found a great stance in pharmacy and medicine and are currently the leading source of drug leads worldwide. It is estimated that about $80 \%$ of world's population depend on medicines of plant origin (WHO, 2003). From these plant sources, scientists have developed numerous drugs including antimicrobials and antioxidants. Due to the acceptance of alternative forms of health care and the development of microbial resistance to available antibiotics, researchers are geared towards investigating the antimicrobial activity of medicinal plants (Lis-Balchin and Deans, 1996).

Antimicrobials treat infections caused by microorganisms. Currently, microorganisms have developed ways to resist the effects of these antimicrobial agents. This has led to a rise in the global problem which is antimicrobial resistance. In addition to this, the development of nematode and trematode resistance to various groups of anthelmintic agents is a major problem. Development of resistance to 
anthelmintic agents in nematodes has been slow, compared with that of the antimicrobials. However, resistance is becoming widespread, because relatively few chemically dissimilar groups of anthelmintic agents have been introduced over the past several decades. Between the antimicrobials and the anthelmintic agents, the need for new agents of natural sources has become necessary as resistance is on the rise. Hence more plants require screening for these properties in the hopes of developing new agents to take care of the problem of resistance.

Plumbago zeylanica, commonly called Plumbago, "white leadwort", "Ceylon leadwort", "Doctorbush" or "Chitrak" in India, (Nguyen et al., 2004) is a valuable medicinal plant widely used in Africa and Asia for the treatments of common ailments like piles (haemorrhoids), diarrhoea, leprosy, acute inflammation and cuts. Plumbago zeylanica is used as an aphrodisiac to stimulate sexual appetite. It has found use as an abortifacient by some indigenous people in Asia and the Middle East. It is also commonly used to relieve tooth and other dental pains and has been used in the past to eradicate coliform bacteria (Datta and Mishra, 2012). Plumbago zeylanica roots were reported to possess antioxidant, hypolipidemic, anti-atherosclerotic, central nervous system stimulant and anti-fertility properties (Kirtikar and Basu, 1975; Mallikadevi and Paulsamy, 2010). The roots are used as laxative, expectorant, astringent, abortifacient, and in dysentery, cirrhosis, arthritis (Bhattacharjee, 1998; Nadakarni and Nadakarni, 1999).

Studies have shown that Plumbago possess antibacterial, anti-mycotic, antiviral, antiplasmodial, antiinflammatory antiseptic, anti-carcinogenic, leishmanicidal and trypanocidal activity and as such has been used widely in Indian and African traditional medicine to relieve fever and symptoms of malaria, dysentery, rheumatic and other bodily pains, as a laxative, stimulant, expectorant and a diaphoretic agent (Mandavkar and Jalalpure, 2011). Plumbago has also been found to contain alkaloids, phenols and flavonoids, the naphthoquinones plumbagin, 3-biplumbagin, chloroplumbagin, chitranone, and elliptone, the coumarins seselin, 5-methoxyseselin, suberosin and xanthyletin (Jain et al., 2014).

This study is aimed at evaluating the antimicrobial, anthelmintic and antioxidant properties of the methanol and ethyl acetate extracts of the leaves of Plumbago zeylanica.

\section{Materials and methods}

\section{Collection of plant material}

In September 2015, the leaves of the plant were collected in the physique garden of Faculty of Pharmacy and Pharmaceutical Sciences, KNUST, Kumasi, Ghana. It was dried at room temperature $\left(25\right.$ to $\left.28^{\circ} \mathrm{C}\right)$ and then milled into coarse powder with laboratory mill machine. Authentication of plant was done in the Pharmacognosy Department of the Faculty.

\section{Preparation and extraction of plant samples}

Plumbago zeylanica powder was extracted by cold maceration method. Using a Mettler Toledo analytical balance, two $200 \mathrm{~g}$ batches of dried, milled Plumbago zeylanica leaves was weighed in a $1000 \mathrm{~mL}$ beaker and transferred into two stoppered $2 \mathrm{~L}$ Winchester bottles to be used for extraction. Using a measuring cylinder, $1000 \mathrm{~mL}$ of $80 \% \mathrm{v} / \mathrm{v}$ methanol and $1000 \mathrm{~mL}$ of pure ethyl acetate was added to the respective bottles which were labelled appropriately and allowed to stand at room temperature for a period of at least $72 \mathrm{hrs}$ with daily agitation for $15 \mathrm{~min}$ at $120 \mathrm{rpm}$ using a laboratory shaker. After $72 \mathrm{hrs}$, the resultant mixture was then filtered using a Buckner funnel and vacuum pump to obtain a supernatant of extract. This was done until enough extract was collected. After filtration, the filtrate was concentrated with a Buchi rotary evaporator to obtain the crude extract and solvents. The crude extracts were transferred into evaporating dishes and then placed in an oven to dry at $40^{\circ} \mathrm{C}$. The dried crude extracts were stored in a desiccator until ready for use.

\section{Phytochemical analysis}

Phytochemical test on the dried, milled leaves was performed for the presence of alkaloids, glycosides, flavonoids and tannins.(Evans, 2009).

\section{Evaluation of Antimicrobial activity}

\section{Test organisms}

Clinical strains of two gram positive bacteria (Staphylococcus aureus and Streptococcus pyogenes), three gram negative bacteria (Escherichia coli, Pseudomonas aeruginosa and Salmonella typhi) and one fungus (Candida albicans) were used for the studies. 


\section{Preparation of test organisms}

The organisms were cultured in nutrient broth at $37^{\circ} \mathrm{C}$ for $24 \mathrm{hrs}$ prior to the experiment. The turbidity of the actively growing broth cultures was adjusted with sterile distilled water to obtain turbidity optically comparable to that of $0.5 \mathrm{McF}$ arland Standard.

\section{MIC determination by micro-titre broth dilution method}

Using a 96 well microtitre plate (Eloff, 1998), $100 \mathrm{~mL}$ double strength nutrient broth was prepared and sterilised in an autoclave. A quantity of $100 \mu \mathrm{L}$ of the double strength nutrient broth was used to fill each well, $10 \mu \mathrm{L}$ of $24 \mathrm{hrs}$ organism suspension was added as well as calculated volumes of the test samples (extracts and standards) and sterile water to give final concentrations of $2,4,8,16,32$, and $64 \mathrm{mg} / \mathrm{mL}$ of the extracts and selected concentrations of ciprofloxacin and ketoconazole. The microtitre plates were covered and incubated at $37^{\circ} \mathrm{C}$ for $24 \mathrm{hrs}$. After $18-24 \mathrm{hrs}$, a volume of $20 \mu \mathrm{L}$ MTT (3-(4.5-dimethylthiazol-2-yl)-2, 5diphenyltetrazolium bromide) solution was added to the wells and the MIC was determined as the lowest concentration that inhibited the growth of the organisms which was indicated by the absence of purple coloration upon addition of the MTT solution.

\section{Determination of antioxidant activity}

The free radical scavenging activity of the extract was determined according to the method described by Agyare et al. (2015) using 1, 1-diphenyl-2-picryl-hydrazyl (DPPH). Extract solutions of concentration 10, 30, 100, $200,300,400,500$ and $1000.0 \mu \mathrm{g} / \mathrm{mL}$ and reference antioxidant (ascorbic acid) concentrations of 4.74, 1.184, $0.592 \mu \mathrm{g} / \mathrm{mL}$ were prepared in methanol. DPPH solution of concentration $0.002 \%$ was also prepared in methanol in a dark room. Three millilitres (mL) of DPPH solution was added to $1.0 \mathrm{~mL}$ of each concentration of extracts and reference antioxidant. The test tubes were kept in the dark for $30 \mathrm{~min}$. After 30min, the absorbance (A1) of excess DPPH in the extracts and standard solutions were measured at $517 \mathrm{~nm}$ using a UV spectrophotometer. The absorbance $\left(\mathrm{A}_{0}\right)$ for a blank solution containing equal volumes of methanol and DPPH was also read and served as a control. The percentage of free radicals scavenged was calculated using the equation:

$$
\% \text { inhibition }=[(\mathrm{Ao}-\mathrm{Al}) / \mathrm{Ao}] \times 100
$$

Inhibitory concentration $\left(\mathrm{IC}_{50}\right)$ was determined as the concentration of samples which scavenged $50 \%$ of free DPPH radicals.

\section{Evaluation of anthelmintic activity}

\section{Collection of worms}

Adult Indian earthworms were collected from water logged area of the soil in Tema Community 10 and cabbage farms in Miotso, near Central University, Ghana. The earthworms of approximately 7 to $18 \mathrm{~cm}$ in length and 0.2 to $0.6 \mathrm{~cm}$ in width were used for the experiment due to its anatomical and physiological resemblance to human intestinal roundworm parasites and also because of easy availability, they used extensively for the preliminary in vitro evaluation of anthelmintic compounds (Tiwari et al., 2011). The earthworms were washed with distilled water to rid them of debris.

\section{Anthelmintic bio-assay}

The worms were divided into four groups each comprising of four earthworms. Ten millilitres of each extract solutions of concentrations 30, 100 and 300 $\mathrm{mg} / \mathrm{mL}$ were prepared using distilled water. Concentrations of $20 \mathrm{mg} / \mathrm{mL}$ albendazole and 150 $\mathrm{mg} / \mathrm{mL}$ piperazine citrate were also used as reference standards. All the samples and the standard drugs were freshly prepared before commencement of the experiments. The earthworms were washed with distilled water and then placed in Petri dishes containing $10 \mathrm{~mL}$ of respective formulation as follows: extracts $(30,100$ and $300 \mathrm{mg} / \mathrm{mL}$ ), piperazine citrate at $150 \mathrm{mg} / \mathrm{mL}$ and albendazole at $20 \mathrm{mg} / \mathrm{mL}$. Observations were made for the time taken to paralyse and death of individual worms. Paralysis was noted when the worms ceased to move but were revived when shaken or placed in warm water of $50^{\circ} \mathrm{C}$. Death was noted when the worms lost motility coupled with a fading away of their body colour. Normal saline was used as negative controls and respective death and paralysis times were recorded (Bhawar et al., 2009).

\section{Statistical analysis}

All results and graphs were plotted and analysed using the Graph Pad Prism 5.0 for windows (Graph Pad software, San Diego, CA, USA) and analysed by twoway ANOVA followed by Bonferroni post-test analysis which recognizes $* p<0.05, * * p<0.01$ and $* * * p<0.001$ as statistically significant. 


\section{Results}

\section{Phytochemical screening}

Phytochemical screening of the plant extracts revealed the presence of tannins, saponins, glycosides, flavonoids and alkaloids.

\section{Antimicrobial activity of Plumbago zeylanica}

The methanol and ethyl acetate extracts of Plumbago zeylanica demonstrated both antibacterial and antifungal activity against all the test organisms. Their antibacterial activity was evident on both Gram-positive and Gramnegative bacteria as shown in Table 1 below.

Table 1. MIC of Plumbago zeylanica extracts and standards.

\begin{tabular}{lllll}
\hline \multirow{2}{*}{ Organisms } & \multicolumn{2}{l}{ Minimum Inhibitory Concentration (MIC) $\mathbf{~ m g} \mathbf{m L}$} & & \\
\cline { 2 - 5 } & Methanol extract & Ethyl acetate extract & Ciprofloxacin & Ketoconazole \\
\hline Staphylococcus aureus & 32 & 16 & 1.5625 & ND \\
Streptococcus pyogenes & 32 & 8 & 1.5625 & ND \\
Escherichia coli & 32 & 16 & 1.5625 & ND \\
Pseudomonas aeruginosa & 16 & 16 & 1.5625 & ND \\
Salmonella typhi & 16 & 16 & 1.5625 & ND \\
Candida albicans & 8 & 16 & ND & 0.05 \\
\hline
\end{tabular}

Key: ND= Not Determined.

\section{Antioxidant activity of Plumbago zeylanica}

Ethyl acetate extract of Plumbago zeylanica showed higher free radical scavenging activity compared to methanol extract. Table 2 shows the concentrations of samples which scavenged $50 \%$ of free radicals. The $\%$ scavenging activity of ascorbic acid and the extracts of Plumbago zeylanica is given in Fig. 1.

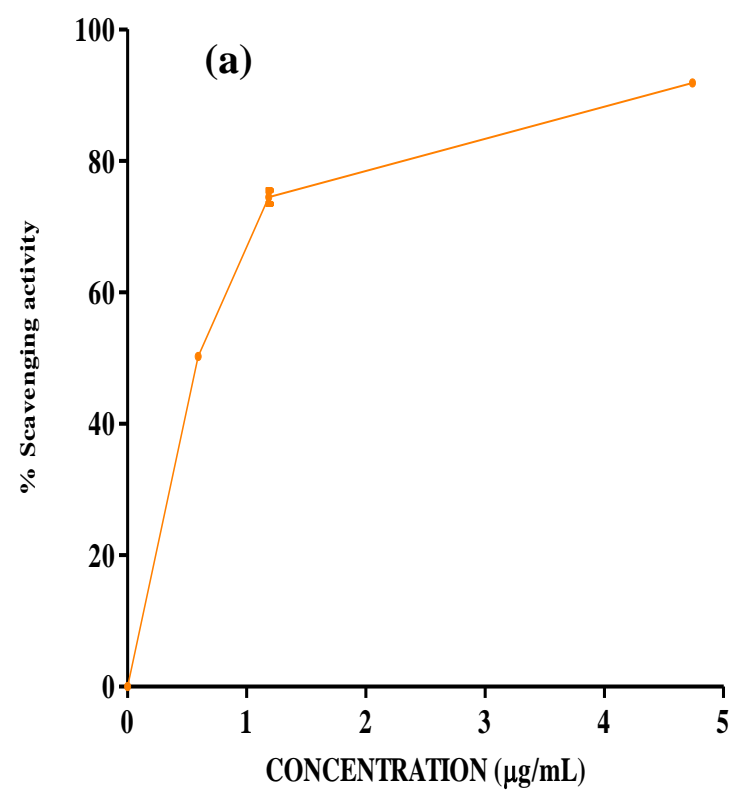

Table 2. Concentration that gives $50 \%$ reduction in DPPH $\left(\mathrm{IC}_{50}\right)$.

\begin{tabular}{ll}
\hline Test sample & $\mathbf{I C}_{\mathbf{5 0}}(\boldsymbol{\mu} \mathbf{g} / \mathbf{m L})$ \\
\hline Methanol extract & 2.33 \\
Ethyl acetate extract & 0.29 \\
Ascorbic acid & $6.298 \times 10^{-5}$ \\
\hline
\end{tabular}

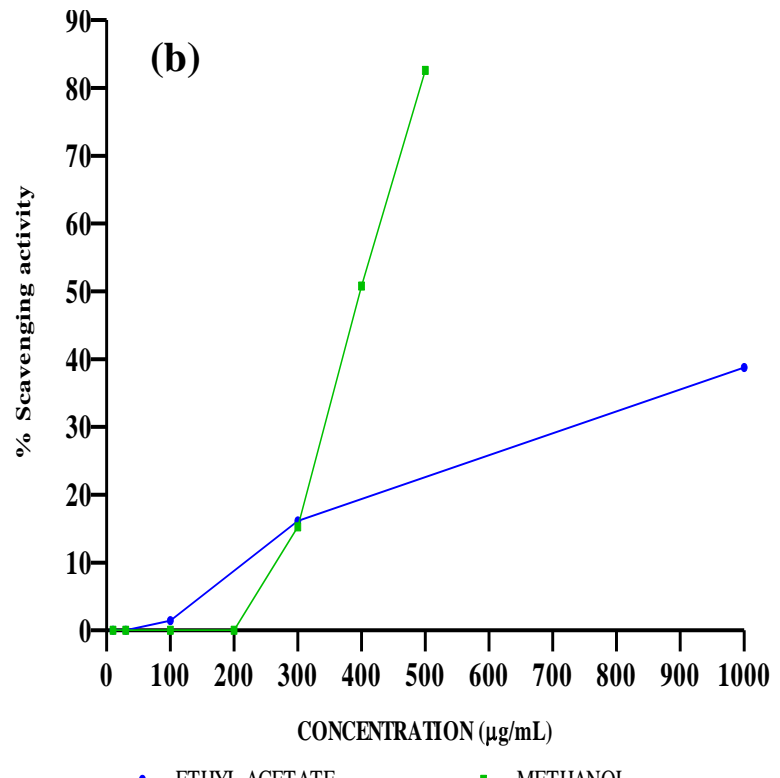

$\rightarrow$ ETHYL ACETATE $\quad \because$ METHANOL

Fig. 1: Scavenging (\%) activity of (a) standard (ascorbic acid) and (b) Plumbago zeylanica extracts.

\section{Anthelmintic activity of Plumbago zeylanica}

All of the three concentrations of extracts of Plumbago zeylanica leaves showed significant dose dependent anthelmintic activity against earthworm, Pheretima posthuma. However, results clearly indicated that 300 $\mathrm{mg} / \mathrm{ml}$ concentration of the extract has the highest potency as an anthelmintic. Ethyl acetate extract of Plumbago zeylanica demonstrated a higher paralysis and death potential than methanol extract (Table 3; Fig. 2). 

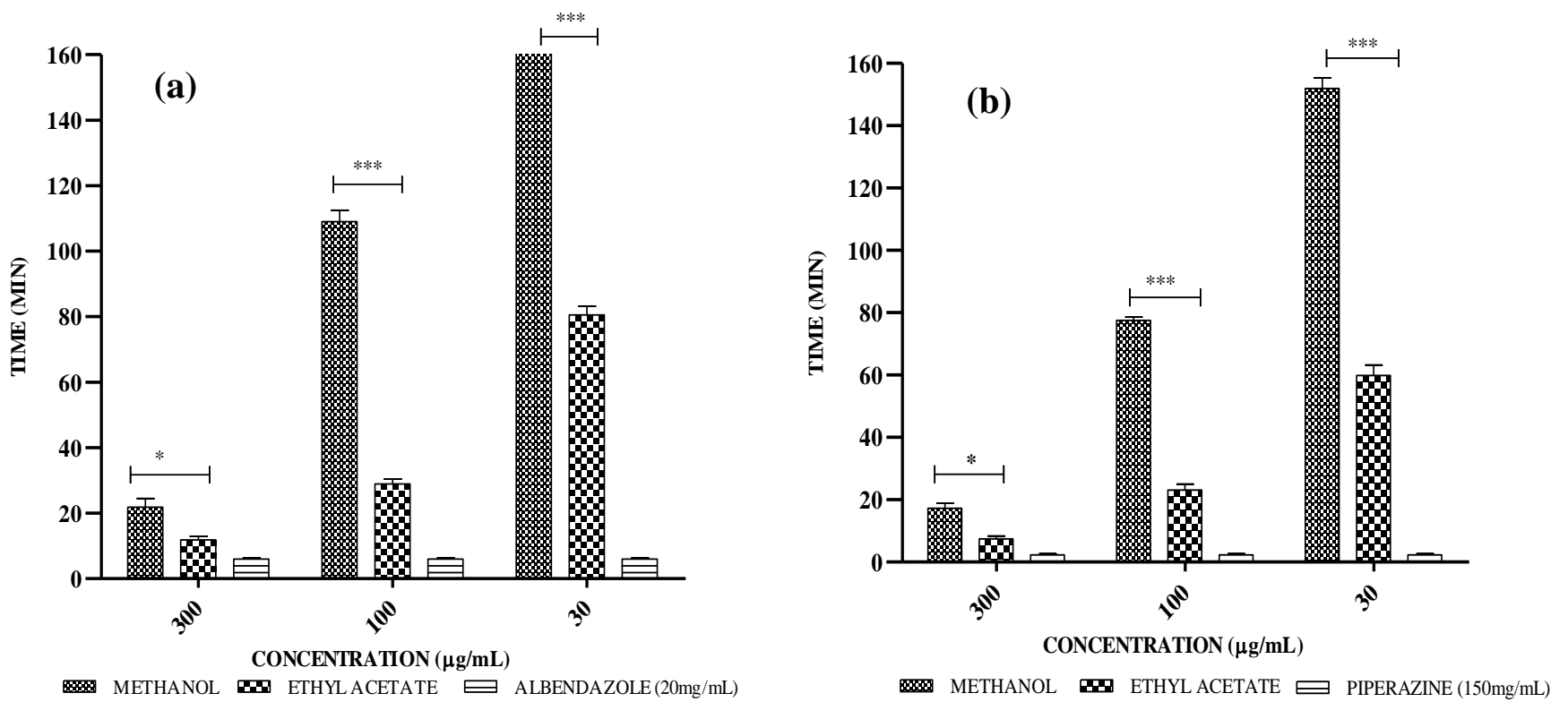

Fig. 2: Effect of Plumbago zeylanica extracts on paralysis of Pheretima posthuma in comparison with (a) Albendazole $(20 \mathrm{mg} / \mathrm{mL})$ and (b) Piperazine $(150 \mathrm{mg} / \mathrm{mL})$ [*** $p<0.0001 ; * p<0.05]$.

Table 3. Anthelmintic activities of Plumbago zeylanica extracts.

\begin{tabular}{lllll}
\hline Treatment & $\begin{array}{l}\text { Concentration } \\
(\mathbf{m g} / \mathbf{m L})\end{array}$ & Groups & $\begin{array}{l}\text { Time of paralysis (min) } \\
\text { (Mean } \pm \text { SEM) }\end{array}$ & $\begin{array}{l}\text { Time of death (min) } \\
(\mathbf{M e a n} \pm \text { SEM) }\end{array}$ \\
\hline Saline 0.9\% & - & 1 & - & - \\
Albendazole & 20 & 2 & ND & 5.980 .31 \\
Piperazine & 150 & 3 & 2.310 .38 & ND \\
Methanol extract & 300 & 4 & $17.231 .68^{* * *}$ & 21.832 .60 \\
& 100 & 5 & $77.511 .12^{* * *}$ & 109.03 .50 \\
& 30 & 6 & $151.193 .45^{*}$ & 162.92 .30 \\
Ethyl acetate extract & 300 & 7 & $7.390 .94 * * *$ & 11.811 .10 \\
& 100 & 9 & $23.101 .90^{* * *}$ & 28.941 .49 \\
& 30 & 10 & $59.853 .35^{*}$ & 80.552 .66 \\
\hline
\end{tabular}

SEM: Standard error mean, $* * * p<0.0001 ;{ }^{*} p<0.05$; ND: Not Determined; - no activity.

\section{Discussion}

Preliminary phytochemical screening of Plumbago zeylanica revealed the presence of alkaloids, glycosides (general as well as saponins and anthracene), flavonoids and tannins. These photochemical constituents are known to play a role in the plants use and its significant medicinal character. Both the methanol and ethyl acetate extracts exerted antibacterial and antifungal activities against the test organisms. The methanol extract possesses a greater inhibitory action against Candida albicans than the ethyl acetate extract whilst the ethyl acetate extract has increased potency against the bacterial organisms. Alkaloids are complex compounds, which have chemical properties that are related to high toxicity and remarkable pharmacological activity. According to
Chavasco et al. (2014), isolated compounds from plant extracts rich in alkaloids have demonstrated antimicrobial activity in several studies (Osborn, 2003). The antimicrobial activity of flavonoids is also established due to their ability to complex with extracellular and soluble proteins and also with the bacterial cell wall. The mechanism of the antimicrobial action of tannins can be explained as causing inhibiting of bacterial and fungal enzymes and complexing with the enzyme substrates. Hence, the antimicrobial activity of Plumbago zeylanica leaves may be attributed to the presence of flavonoids, alkaloids and tannins (Kolapo et al., 2009; Apenteng et al., 2014).

The antioxidant activity of the extract was determined using DPPH free radical scavenging method, which 
measures the ability of the extract to scavenge free radicals. The $\mathrm{IC}_{50}$ values, which is the concentration that gives $50 \%$ reduction in DPPH, gives the potency of an agent as an antioxidant. Lower $\mathrm{IC}_{50}$ values indicate increased potency and better free radical scavenging activity and vice versa.

The obtained results show that the ethyl acetate extract of Plumbago zeylanica has better antioxidant activity than the methanol extract as indicated in the $\mathrm{IC}_{50}$ values in Table 2. The antioxidant activity of these extracts may be attributed to the presence of the identified phytochemicals such as flavonoids and tannins which are phenolic compounds. Studies have shown that plant phenolics are a major group of compounds that act as primary antioxidants or free radical scavengers (Potterat, 1997).

The methanol and ethyl acetate extracts of Plumbago zeylanica showed significant anthelminthic activity at $30 \quad(p<0.001), 100 \quad(p<0.001)$ and $300 \mathrm{mg} / \mathrm{mL}$ $(p<0.05)$. Plumbago zeylanica tested positive for the presence of alkaloids, tannins, flavonoids and other significant phytochemicals. Alkaloids are known to have effects on the central nervous system hence effects like paralysis are observed (Tiwari et al., 2011). The bioactivity of alkaloids on central nervous system also works for worms as observed in the inhibition by the two plant extracts. From the results above, the ethyl acetate extract possess a significantly higher activity as an anthelminthic than the methanol extract. The reason for this significant difference may be due to the enhanced quantity of alkaloids present in the ethyl acetate extract.

\section{Conclusion}

Plumbago zeylanica leaf extracts exert anti-infective and antioxidant activity. Ethyl acetate extracts possess better biological activity than methanol extract.

\section{Conflict of interest statement}

Authors declare that they have no conflict of interest.

\section{Acknowledgement}

Authors acknowledge the contribution Mr. Kwame Koomson and Mr. Harry Oblie, Laryea of the Department of Pharmaceutical Science, Central University for their technical support. We also appreciate the contribution of Mr. Kakraba of the department of
Pharmacognosy, KNUST, Kumasi for the plant collections and preparation.

\section{References}

Agyare, C., Baiden, E., Apenteng, J.A., Boakye, Y.B., AduAmoah, L., 2015. Anti-infective and anti-inflammatory properties of Portulaca oleraceae (L). Donn. J. Med. Plant Res. 2(1), 1-6.

Apenteng, J.A., Agyare, C., Adu, F., Ayande, G.A., Boakye, Y.D., 2014. Evaluation of the wound healing potential of different leaf extracts of Pupalia lappacea. Afr.J. Pharm. Pharmacol. 8, 1006-1011.

Bhattacharjee, S. K., 1998. Hand Book of Medicinal Plants. Pointer Publishers, Jaipur, India. 274p.

Bhawar, G.B., Bhalke, R.D., Lodha, K.R., Karmase, B.C., Londhe, C.D., 2009. Phytochemical investigation and in vitro anthelmintic activity of Bauhinia racemosa (L) (Leguminosae). Pharmacol. 1, 300-303.

Chavasco, J. M., Prado Feliphe, B. H. M., Cerdeira, C. D., Leandron, F. D., Coelho, L. F. L., De Silva, J. J., Chavasco, J. K., Dias, A. L. T., 2014. Evaluation of antimicrobial and cytotoxic activities of plant extracts from southern Minas Gerais Cerrado. Rev. Inst. Med. Trop. Sao Paolo. 56(1), 13-20.

Datta, S., Mishra, R., 2102. Plumbago zeylinica Linn. (Chitrak) - Review as Rasayan (Rejuvenator / Antiaging). Int. J. Res. Pharmaceut. Biomed. Sci. 3(1), 250-267.

Eloff, J. N., 1998. A sensitive and quick method to determine the minimum inhibitory concentration of plant extract for bacteria. Plant Med. 64, 711-713.

Evans, W.C., 2009. Trease and Evans Pharmacognosy. $16^{\text {th }}$ Edn.Saunders, Elsevier, London,UK.

Jain, P., Sharma, H. P., Basri, F., Baraik, B., Kumari, S., Pathak, C., 2014. Pharmacological profiles of ethnomedicinal plant: Plumbago zeylanica L. A review. Int. J. Pharm. Sci. Rev. Res. 24(1), 157-163.

Kirtikar, K.R., Basu, B.D. (Eds.), 1987. Indian Medicinal Plants. Vol. 3. $2^{\text {nd }}$ Edn. International Book Distributors, Dehra Dun, India.

Kolapo, A.L., Okunade, M.B., Adejumobi, J.A., Ogundiya, M.O., 2009. Phytochemical composition and antimicrobial activity of Prosopis africana against selected oral pathogens. World. J. Agric. Sci. 5, 90-93.

Lis-Balchin, M., Deans, S.., 1996. Antimicrobial effects of hydrophillic extracts of Pelargonium species. Appl. Microbiol. 23(4), 205-207.

Mallikadevi, T., Paulsamy, S., 2010. Plumbago zeylanica a potential plant for antimicrobial activity. Plant Arch. 10, 547-550.

Mandavkar, Y.D., Jalalpure, S.S., 2011. A comprehensive review on Plumbago zeylanica Linn. Afr. J. Pharm. Pharmacol. 5(25), 2738-2747.

Nadakarni, A. K., Nadakarni, K. R., 1999. Indian-Materia Medica. Popular Prakashan, Bombay, India. 564p.

Nguyen, A.T., Malonne, H., Duez, P., Vahaelen-Fastre, R., 
Vanhaelen, M., Fontaine, J., 2004. Cytotoxic constituents from Plumbago zeylanica. Fitoterapia. 75(5), 500-504.

Osborn, A. E., 2003. Saponins in Cereals. Phytochem. 62, 1-4.

Potterat, O., 1997. Antioxidants and free radical scavengers of natural origin. Curr. Organic Chem. 1(4), 415-440.

Tiwari, P., Kumar B., Kumar M., Kaur M., Debnath J., Sharma
P., 2011. Comparative anthelmintic activity of aqueous and ethanolic stem extract of Tinospora cordifolia. Int. J. Drug. Dev. Res 3(1), 70-83.

WHO, 2003. World Health Report available at: http://www.who.int/whr/2003/en/ assessed on 21/07/2016 at 10:00 GMT.

\section{How to cite this article:}

Apenteng, J. A., Brookman-Amissah, M. G., Osei-Asare, C., Oppong, E. E., Ogundeyi, M., 2016. In vitro antiinfective and antioxidant activity of Plumbago zeylanica Linn. Int. J. Curr. Res. Biosci. Plant Biol. 3(8), 131137. doi: http://dx.doi.org/10.20546/ijcrbp.2016.308.020 